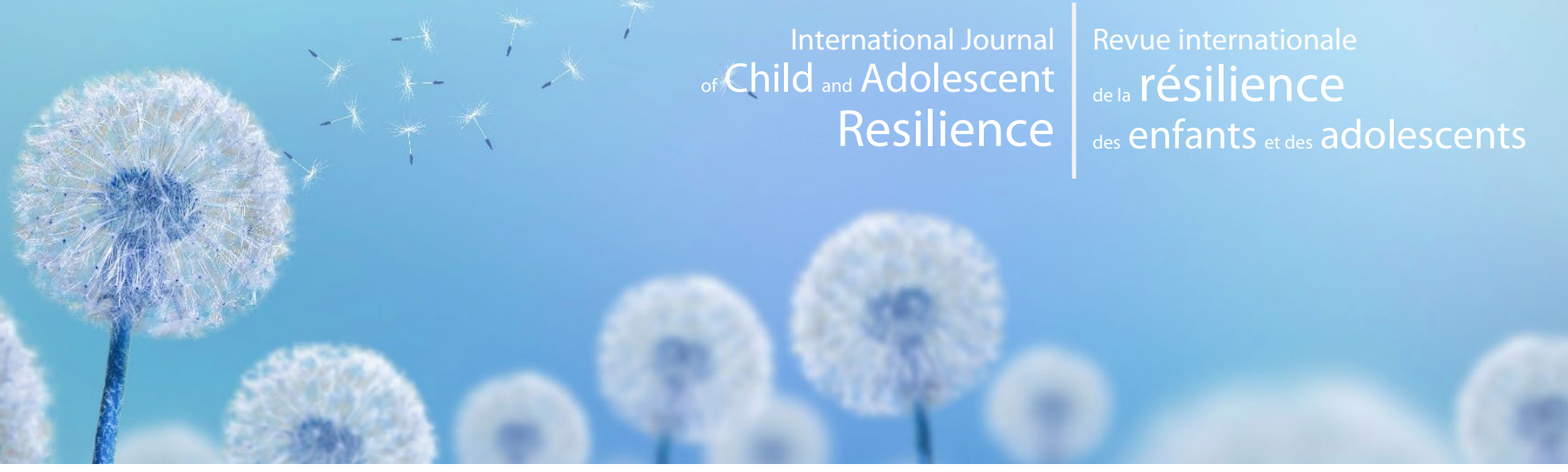

\title{
Instagram as a knowledge mobilization platform for youth resilience research: An exploratory study
}

\section{Negar VAKILI', Sherry. H STEWART', Savanah SMITH' ${ }^{2}$, Annphin MATHEW ${ }^{2}$, and Christine WEKERLE²}

Departments of Psychiatry, Psychology and Neuroscience and Community Health and Epidemiology, Dalhousie University

2 Department of Pediatrics, McMaster University

Corresponding Author: Savanah Smith, Department of Pediatrics, McMaster University, 1200 Main St. West, Hamilton, Ontario, Canada L8N $3 Z 5$.

Email: smiths73@mcmaster.ca.

\section{Abstract}

Objectives: Social media (SoMe) is globally prevalent, but its relevance for disseminating sensitive topics, such as violence victimization and mental health among adolescents and emerging adults, remain under-researched. Youthdominate platforms may be well-suited for resilience messaging on safety, health, and well-being, and exploratory knowledge mobilization research. Research from a common team funding source supported a secondary objective that thematically linked research could be used to impact dissemination.

Methods: This experiment utilized an ABA design, with a two-week baseline, followed by SoMe posting on weeks "A" and no posting on weeks " $\mathrm{B}$ " from a single Instagram account. During posting weeks, image-based messages from nine open access articles, from a risk and resilience research team, were posted three times per day. Each post contained a link to the associated open-access research article. Outcome dissemination indices, collected weekly, were reads of the referenced articles on a research-based networking site, ResearchGate.

Results: Instagram indices formed the basis of our manipulation check. Relative to periods of inactivity, periods of active Instagram engagement led to significant increases in the number of Instagram impressions, website clicks, and followers, and in the number of reads of the posted ResearchGate articles.

Implications: As the first study to examine Instagram impact for risk and resilience research, these findings encourage further SoMe work in this area of high public health import.

Keywords: Instagram; knowledge mobilization; research impact; social media; youth; risk; resilience; public health. 
Instagram as a knowledge mobilization platform for youth resilience research: An exploratory study

\section{Introduction}

The adolescent to young adult time period is one that benefits from the promotion of resilience, given the multiple changing roles (i.e., entry into romantic relationships, labour market, higher education, etc.). Resilience has been described as an individual's capacity to access resources during adversity in ways that promote their health and well-being; it is contextualized with surrounding socio-cultural opportunities or lack thereof (Ungar, 2008). To support youth development in contexts of adversity, youths' inner resourcefulness is amplified by availability and access to environmental resources (Wekerle et al., 2011). Resilience-focused support may smooth transitions and assist in maintaining stable emotion regulation and cognitive organization (Ungar \& Theron, 2020); this would facilitate addressing challenging life circumstances in which youth or the peers they wish to support may find themselves. From adolescence to emergent adulthood, which have been defined as age ranges 10-19 and 18-25 respectively, the brain regions responsible for decision making and the regulation of social behaviour are developing, and risk of the development of psychological problems is heightened (World Health Organization, 2018; Arnett, 2000; Lamblin et al., 2017). Youth are also moving towards greater autonomy and independent decision-making, which extends to their healthcare and wellness: about one-fifth of youth are seeking information online regarding hard-to-discuss topics, like sexual disease, mental health, and substance use (Lenhart et al., 2010).

There are many issues with which youth are contending. For example, the 2017 US Center for Disease Control's Youth Risk Behavior Survey reported that 11.3\% of females and 3.5\% of male students have been physically forced into having sexual intercourse (Kann et al., 2018). Among youth who identified as gay, lesbian or bisexual, this rate was much higher (21.9\%), as well as among those who were questioning or "not sure" of their sexual identity (13.1\%). Other data shows that in the prior 12 months, 9.7\% of students reported being "forced to do sexual things that they did not want to do" (Ortiz et al., 2018). Among youth involved in a dating relationship in the prior 12 months, sexual dating violence was reported by 6.9\%. Further, a staggering 31.5\% of students reported feeling sad or hopeless almost every day over the prior two weeks, such that they stopped doing some of their usual activities (Kann et al., 2018). In a similar vein, 30\% of Ontario youth reported elevated stress or pressure in their lives, and 39\% reported distress symptoms (i.e., anxiety and depression symptoms) at a moderate-to-severe level. Youth are clearly reporting salient and significant adversity, and social media (SoMe) may be a tool for their resilience. As such, this study explores the Instagram social networking platform as a potential knowledge mobilization tool for youth health risk and resilience research.

\section{Youth interaction with SoMe}

Theoretically, Bronfenbrenner's ecological approach (1979) has been commonly used in resilience formations (O'Connell et al., 2009), as it takes into account how ecological systems interact with and around the individual to elevate risk or promote resilience through external factors and processes (e.g., the family context, social relationships, societal and cultural values, etc.; Mustanski et al., 2011). Within ecological theory, the individual interacts and establishes their identity within multiple microsystems (i.e., interpersonal relationships and roles within their immediate setting; e.g., home, school, and their community), mesosystems (i.e., settings in which microsystems interact), exosystems (i.e., interactions among two or more of the settings, where the individual is not directly involved with at least one of these settings), and macrosystems (i.e., organization and culture) (Bronfenbrenner, 1979; Bronfenbrenner, 2005). With the rise in availability and accessibility of technology and digital platforms, especially among adolescents and emergent adults, Bronfenbrennor's ecological model $(1979 ; 2005)$ must be expanded to consider how SoMe has become interwoven throughout and interacts with these systems (Eaton, 2014). According to recent data, 95\% of adolescents have access to a smartphone (Pew Research Center, 2018a) with 54\% reporting that they spend "too much" time on them (Pew Research Center, 2018b). O'Keeffe and Clark-Pearson (2011), found that 22\% of young adults visit SoMe sites more than 10 times daily. Ninety-two percent of youth reported to the Pew Research Centre that they use the internet on a daily basis. Twenty-four percent out of those 92\% described being on their SoMe accounts 'constantly' (Lenhart, 2015). With SoMe, most adolescents (71\%) are using more than one platform (Lenhart et al., 2015). The various SoMe platforms (e.g., Instagram, Facebook, Snapchat, Twitter, TikTok, YouTube) may be perceived as microsystems in which the individual learns to navigate their constructed identities. These platforms interact with other systems that the individual is connected to, such as school or home (i.e., mesosystems) and, ultimately, shape youth culture, ideals, values and beliefs (i.e., macrosystems) (Easton, 2014).

A qualitative study of SoMe users has identified 10 key uses and gratifications for SoMe: 1) social interaction; 2) finding information on different topics; 3) passing time, 4) entertainment, 5) relaxation; 6) communication; 7) convenience; 8) to express opinions; 9) information sharing; and 10) checking up on others and gaining knowledge 
Instagram as a knowledge mobilization platform for youth resilience research: An exploratory study

about them (Whiting \& Williams, 2013). SoMe use among youth has been associated with growth of ideas, development of self (Ahn, 2014; Rushing \& Stephens, 2011; O'Keeffe \& Clarke-Pearson, 2011; Valkenburg et al., 2006). Within the context of adversity, resilience has been defined as "both the capacity of individuals to navigate their way to health-sustaining resources, including opportunities to experience feelings of well-being, and a condition of the individual's family, community and culture to provide these health resources and experiences in culturally meaningful ways" (Ungar, 2008, p. 225). This definition emphasizes culturally meaningful means of access. For youth, new media has been ingrained in their identity formation and has transformed youth culture (Zemmels, 2012).

\section{SoMe as a tool for youth knowledge mobilization}

Youth tend to prefer more informal sources of support in terms of information, communication and helpseeking (D'Avanzo et al., 2012; Pretorius et al., 2019). In fact, 39\% of students report that they do not talk to parents about their problems or feelings (Boak et al., 2017). Advice and support are being sought out by youth through digital channels such as text messaging, private messaging, and online chats (Child Helpline International, 2014). A report from Childline (i.e., a UK children's helpline) indicates that $78 \%$ of young people that contact their services, do so online (Frith, 2017). SoMe has quickened the speed of access to health information and holds promise for public health as it is costeffective, publicly accessible, and relatively low-effort in terms of maintenance (Dowshen et al., 2015). While females have been shown to be more likely to search online about uncomfortable health topics (Lenhart et al., 2010), one study of adolescent males found that $48 \%$ were using SoMe sites to retrieve health-related information (Best et al., 2016). It is believed that this increase in SoMe use by youth may be associated with the convenience and anonymity of accessing stigmatized health information, such as sexual infections, substance use, or sexual victimization (O'Keeffe \& ClarkePearson, 2011). In a nationally representative survey of US adolescents, stress and anxiety were the third most commonly searched health-related topic, after exercise and diet/nutrition (Wartella et al., 2016). Additionally, among youth who searched for health information online, 34\% reported changing their behavior, based on the information found. For older adolescents (15-18 years) and emerging adults, health analysis on scalable interventions suggests a mixed approach of involving community, media and health systems, where media messages on healthy lifestyle choices at the population level, would be supported by school-based programming, community services, and primary health care (Bundy et al., 2017).

\section{Using SoMe for youth resilience promotion}

Informational self-efficacy is both a key public health literacy approach, as well as a facilitator of youth resiliency skills. Resilience is critical to achieve positive health outcomes as individuals face various developmental transitions. Most SoMe health campaigns or interventions that have been studied have focused on sexually transmitted infections, sexual health and male health initiatives (e.g., Bull et al., 2012; Lenhart et al., 2010; Ortiz et al., 2018; Zenone et al., 2020). In one nationally representative US study of 1337 young people (age 14 to 22), 90\% of participants with moderate-tosevere depressive symptoms endorsed going online for information on mental health issues (Rideout et al., 2018). They were also nearly twice as likely (25\%) to report that SoMe connects them to useful advice and supports when experiencing feelings of depression, anxiety, and/or stress, in comparison to those with no mental health symptoms. Additionally, they were more likely to report that SoMe was 'very important' to them for feeling less alone (30\%), getting inspiration from others (27\%), and expressing themselves creatively (26\%). A systematic review of online and SoMe interventions for young people with depression found evidence toward the effectiveness of online interventions, especially those that utilize cognitive behavioural therapy principles (Rice et al., 2014). However, they noted that SoMe intervention evidence in this domain is limited due to poor methodological design and very few interventions having been developed to date. Studies have found SoMe platforms such as Instagram, Facebook, Twitter, Reddit, and Tumblr to be effective in recruiting participants with mental health concerns (Szlyk et al., 2020), thus reinforcing the notion that these platforms may be opportune in engaging users with mental health and resilience promotion information.

Qualitative interviews with LGBTQ adolescents, aged 18 to $22(n=19)$, revealed four resilience strategies that were fostered through their use of media and SoMe forums: 1) coping with daily stressors or stigma through escapism; 2) feeling stronger through suicide prevention, instructional videos and learning and identifying positive role models; 3) fighting back by commenting on and creating content about discrimination, homophobia and transphobia; and (4) finding and fostering community (Craig et al., 2015). The linkages between SoMe and resilience have been studied in other domains such as student resilience, resilience following natural disasters, and within remote Indigenous communities (Sigalit et al., 2017; Dufty, 2012; Taylor et al., 2012; Kaufmann, 2015). For example, several research studies have examined how SoMe promotes resilience in crisis situations and natural disasters through gathering and 
Instagram as a knowledge mobilization platform for youth resilience research: An exploratory study

disseminating information, collaborative problem-solving and increasing sense-making, and the use of positive coping strategies such as community connectedness (Jurgens \& Helsloot, 2018; Taylor et al., 2012; Kauffman, 2015). However, to our knowledge, the use of social media for the dissemination of adolescent resilience-oriented content has not yet been investigated.

The promotion of resilience-based information through SoMe has the potential to engage youth in a way that is part of the fabric of their social lives. One SoMe health campaign used many text- and visuals-based SoMe platforms to spread information about adolescent dating violence (Lambert et al., 2014). Effectiveness of the campaign was measured by frequency of visits to the posted content. The researchers found that using technology appropriate for the target age group, timing of message delivery, length, context, and type of message were critical factors in engaging their target population. The topic of sexual violence victimization was the primary focus in another recent Twitter study demonstrating that actively engaging followers with posts and the sharing of research could be effectively used to direct users to other online sources (Wekerle et al., 2017). In this study, Twitter postings with links to the articles on a research-sharing site (i.e., ResearchGate) led to an increase in the number of downloads and citations, as compared to timeframes where no postings occurred. These findings suggest potential for use of SoMe in the youth resilience field.

The popular visual-based SoMe application, Instagram, provides a potential avenue to share health-related risk and resilience messages with the public. This platform is especially well-suited to adolescents and emerging adults, given that 73\% of youth, aged 12-24 years, report using it (Edison Research \& Triton Digital, 2017). Instagram is an online photo-sharing networking service that allows users to capture, edit, and share photos and videos with their followers as well as other users using their mobile devices (Sheldon \& Bryant, 2016). Users must create an account with an attached handle (to heighten privacy) with which they can follow the accounts of individuals and organizations to view their posts (Hu et al., 2014), as well as having private settings where would-be followers need to be invited. Image posts can be captioned with a brief description or message, and up to 30 hashtags. Hashtags are words prepended with ' $\#$ ' that are used on popular social media platforms (such as Instagram, Facebook, and Twitter) to identify the content of the picture with which they are paired, therefore allowing users to search for posts that they are interested in and potentially increase the visibility of a user's post by allowing other users to more easily locate it (e.g. \#youth, \#resilience, \#sexualviolence, \#lifestyles, \#health) (Giannoulakis \& Tsapatsoulis, 2016; Hu et al., 2014). Hashtags can also be used as a tool to gage topic interest by examining the number of followers for related hashtags and selecting high-usage hashtags.

Few studies, however, have been conducted using Instagram for knowledge mobilization purposes. One study aimed at improving knowledge and testing for sexually-transmitted infections and HIV among youth aged 1317 years (Dowshen et al., 2015). The number of account followers on Instagram was used to measure the success of the campaign in engaging with the target population. The large number of followers showed the feasibility of such an approach; however, this outcome measure is problematic as a sole index of engagement, as users who do not follow the Instagram account may still view, comment, like, tag friends' accounts, or send the post to others, yet are not counted when followers is used as the outcome. Research on an adolescent male health initiative campaign found that engaging young people with both print media posters and social media posts on Instagram and Snapchat and linking to the campaign resources, increased their website traffic by $70 \%$ and increased awareness of the program in the target populations by 10 to 15\%. On Instagram alone, the campaign posts were viewed by over 170,000 individuals and the resource website link was clicked approximately 2467 times (Zenone et al., 2020). Another study looked at the impact of sharing sexual health information on Instagram using four different methods: 1) adding text to a background image; 2) posting a related image with the sexual health information in the description; 3) posting the sexual health information in both the photo and the description; and 4) posting a photo with no text information. They showed that adding text to a background image received the highest perceived message effectiveness ratings (O'Donnell \& Willoughby, 2017). Few SoMe studies have been conducted examining engagement through the sharing of academic research with members of the public outside of academia, and particularly in terms of the sensitive health content that adolescents and emerging adults seek (Zardo et al., 2018). 


\section{The current study}

This exploratory study was conducted to investigate the effectiveness of Instagram as a knowledge mobilization tool for sharing research information about risk and resilience in youth. Research-based posts, linked to an open-access article available on an article sharing platform, ResearchGate, were shared on Instagram, and the level of engagement by users was measured. Non-research article posts on resilience were also shared on Instagram as a method for raising public interest in the topic of resilience. This study sought to examine the utility of Instagram for engaging users with research-based posts, and the research upon which the post was based. Given the demonstrated need and level of interest among youth, it was hypothesized that users would engage with research-based posts on Instagram, and thus be motivated to further access the associated, linked articles on ResearchGate. The number of times the Instagram posts were viewed by Instagram users was utilized as a manipulation check of the Instagram "On" and "Off" conditions. The number of reads for each associated article on ResearchGate were tracked as outcomes to measure effectiveness in engaging users with research on sensitive risk and resilience topics.

\section{Methods}

\section{Participants}

The design of this study is such that the unit of analysis is the research articles being linked to from the posts within the "Instagram On" condition $(n=9)$. The characteristics of the users that followed the @resilienceinyouth account are described within the results section.

\section{Measures}

Analytics were collected weekly throughout the experiment at 12:00 a.m. each Monday (which marked the start of each new experimental week) from both Instagram and ResearchGate.

Instagram Insights (the analytics package for Instagram) was accessed to collect data from one Instagram account, @resilienceinyouth, newly set up to share thematically linked resilience research (trauma and coping) from a single, federally funded team of researchers, with a unique hashtag (\#CIHRTeamSV). Three sets of information from the Instagram Insights tool was collected: 1) impressions (i.e., the total number of times the Instagram posts have been seen); 2) website clicks (i.e., the number of times individuals clicked on the link embedded in the Instagram post); and 3) followers (i.e., total number of Instagram followers). A baseline (pre-posting) measurement for each of these variables was taken to help ensure that any change in engagement was due to the Instagram posting experimental manipulation.

From ResearchGate, the number of reads for all articles shared via Instagram during the experiment was collected each week, in order to observe how effectively knowledge shared on Instagram facilitated traffic to ResearchGate (see Table 1 for the list of articles and links to ResearchGate). The criteria for choosing the articles listed in Table 1 were: a) to be recent (published between 2015 to 2018); b) to be open access; c) to be from one of the CIHRTeamSV research leads. This provided us with nine eligible articles to disseminate. A baseline measurement for the number of reads of each article was taken to help ensure the change in engagement was due to the Instagram posting, as opposed to researcher or article popularity.

\section{Materials}

Information on the weekly statistics from both Instagram and ResearchGate. Instagram Analytics data were used to determine the level of the participants' activity on Instagram. The Instagram Insights page was accessed by research assistants via the following link: https://www.instagram.com/resilienceinyouth/?hl=en. This link provided data on the number of impressions, website clicks, followers each week which was a cumulative variable (i.e., followers tend to accumulate over time). ResearchGate Stats data were used to determine the level of knowledge mobilization via traffic to ResearchGate articles and as well to the engagement on the posts. The ResearchGate Stats page was accessed for each article (see Table 1). This provided data on number of research interests, number of reads, number of citations, and recommendations on Research Gate each week which were used as our dependent measures. 
Table 1. List of linked open-access research articles used in posts.

\begin{tabular}{|c|c|c|}
\hline$\#$ & Article reference & ResearchGate link \\
\hline 1 & $\begin{array}{l}\text { Smith, M. M., Vidovic, V., Sherry, S. B., Stewart, S. H., \& Saklofske, D. H. (2018). Are perfectionism dimensions risk } \\
\text { factors for anxiety symptoms? A meta-analysis of } 11 \text { longitudinal studies. Anxiety, Stress, \& Coping, 37(1), 4-20. }\end{array}$ & https://bit.ly/2msXN2m \\
\hline 2 & $\begin{array}{l}\text { Keough, M. T., Battista, S. R., O'Connor, R. M., Sherry, S. B., \& Stewart, S. H. (2016). Getting the party started- } \\
\text { Alone: Solitary predrinking mediates the effect of social anxiety on alcohol-related problems. Addictive } \\
\text { Behaviors, 55, 19-24. }\end{array}$ & https://bit.ly/2oSXajl \\
\hline 3 & $\begin{array}{l}\text { Smith, M. M., Speth, T. A., Sherry, S. B., Saklofske, D. H., Stewart, S. H., \& Glowacka, M. (2017). Is socially prescribed } \\
\text { perfectionism veridical? A new take on the stressfulness of perfectionism. Personality and Individual Differences, } \\
110,115-118 .\end{array}$ & https://bit.ly/2iY5WMp \\
\hline 4 & $\begin{array}{l}\text { Goldstein, A.L., Zhu, J. Y., Kofler, D., Wekerle, C. (2016). Child maltreatment, altered self-capacities and resilience: } \\
\text { Testing a moderated mediation model of depression symptoms and alcohol problems in emerging adulthood. } \\
\text { International Journal of Child and Adolescent Resilience, 4(1), 122-141. }\end{array}$ & https://bit.ly/2GCu5D0 \\
\hline 5 & $\begin{array}{l}\text { Ellenbogen, S., Trocmé, N., Wekerle, C., \& McLeod, K. (2015). An Exploratory Study of Physical Abuse-Related } \\
\text { Shame, Guilt, and Blame in a Sample of Youth Receiving Child Protective Services: Links to Maltreatment, Anger, } \\
\text { and Aggression. Journal of Aggression, Maltreatment \& Trauma, 24(5), 532-551. }\end{array}$ & https://bit.ly/2DctBOb \\
\hline 6 & $\begin{array}{l}\text { Wekerle, C., Goldstein, A. L., Tanaka, M., \& Tonmyr, L. (2017). Childhood sexual abuse, sexual motives, and } \\
\text { adolescent sexual risk-taking among males and females receiving child welfare services. Child Abuse \& Neglect, } \\
66,101-111 .\end{array}$ & https://bit.ly/2oQAv7F \\
\hline 7 & $\begin{array}{l}\text { Hébert, M., Blais, M., \& Lavoie, F. (2017). Prevalence of teen dating victimization among a representative sample } \\
\text { of high school students in Quebec. International Journal of Clinical and Health Psychology, 17(3), 225-233. }\end{array}$ & https://bit.ly/2FAVh4E \\
\hline 8 & $\begin{array}{l}\text { Hébert, M., Langevin, R., \& Oussaïd, E. (2018). Cumulative childhood trauma, emotion regulation, dissociation, } \\
\text { and behavior problems in school-aged sexual abuse victims. Journal of Affective Disorders, 225, 306-312. }\end{array}$ & https://bit.ly/2FqDie5 \\
\hline 9 & $\begin{array}{l}\text { Hébert, M., Moreau, C., Blais, M., Lavoie, F., \& Guerrier, M. (2017). Child sexual abuse as a risk factor for teen dating } \\
\text { violence: Findings from a representative sample of Quebec youth. Journal of Child \& Adolescent Trauma, 1 Q1), } \\
\text { 51-61. }\end{array}$ & https://bit.ly/2oZlkaa \\
\hline
\end{tabular}

Note. All of the above articles posted on ResearchGate at the time of the study were either open-access publications, or the authors posted preprint (manuscript) versions of the article to comply with journal copyright requirements.

\section{Procedures}

The experiment ran over the course of six weeks (Monday, February 19 to Sunday, March 25, 2018). The Instagram posting campaign was conducted in an AABABA format. ' $A$ ' represented "Instagram Off" weeks, where no posting occurred. The first two of these weeks (i.e., February 12 - February 18 and February 19 - February 25) are referred to as our baseline weeks, as these weeks were uncontaminated by prior attempts to disseminate research findings through the Instagram account. During this two-week baseline period, we did not post anything (e.g., links to articles) on the Instagram account. March 5-March 11 and March 19-March 25 were the subsequent two "Instagram Off" weeks. No Instagram posting occurred during these 'Instagram Off' weeks. 'B' represented "Instagram On" weeks, where regular daily Instagram posting occurred. The two "Instagram On" weeks occurred on February 26 - March 4 and March 12 - March 18, respectively. This type of "reversal" design is useful for helping establish that it was the Instagram postings, as opposed to other factors such as the passage of time or some other factor contiguous with posting, that contributed to the measured outcomes (Kazdin, 2011).

There were two types of posts: 1) general resilience information (non-research study specific) and 2) researchspecific resilience information. Each day, during the "Instagram On" period, three posts were made in random order. Specifically, one general interest, non-research article post on resilience (total $n=15$ ) and two research-based posts specific to a research finding and a research article (total $n=27$ ), were published in a randomized order. On one of the 14 days of posting, there were two general interest (non-research study specific) and one research study-specific article posted. For all posts, the description contained 10 standard resilience-oriented hashtags (i.e., \#ResiliencelnYouth, \#Resilience, \#Wellness, \#WellnessWarrior, \#WellnessJourney, \#Resilient, \#ResilientSquad, \#ResilientFuture, \#Wellbeing, and \#WellnessZone) and five hashtags related to the specific post (e.g., \#EndViolence, \#Research, \#Overcome, \#Strength \#CIHRTeamSV).

A non-research article post was comprised of an image with a general resilience statement displayed in text over the image. For example, some posts contributed to defining concepts of resilience: "Resilience is learning from your struggles."; "Resilience involves making time for the things you love."; "Resilience is endurance." While the team did not directly study the impact of these posts, they were included in the study to raise Instagram users' interest in the 
topic of resilience. The description below the image restated the resilience message and contained 15 relevant hashtags.

A research-based post included an image that shared, in text laid over the image, a resilience-oriented research finding or implication (e.g., "Risk alert: Emotionally abused females are at greater risk of experiencing abuserelated shame"; "Resist the pressure: Having other-oriented perfectionists in your social circle may increase your pressure to be perfect"; "Resilient interventions: Teaching consent is critical - 1 in 5 teen girls reported sexual coercion in early romantic relationships"). These statements were taken from one of nine studies pre-selected to be shared based on the eligibility criteria described above. The description below the image contained the authors' names, title of the article, 15 relevant hashtags, and a link to the article on ResearchGate. This description also indicated that there was a clickable link to the article in the @resilienceinyouth account biography page which users could click on to access the article during the "Instagram On" period. Each article was shared three times throughout the experiment, in three different posts with a different research finding or implication provided.

Instagram posts were made at the same three times each day (10:00 a.m., 1:00 p.m., and 5:00 p.m.), with two research article-based posts and one non-research article post per day in a predetermined random order. The order of the posts by type for each day and the order of the research articles being referred to in the research-based posts were randomized. However, we had no control over the order in which our followers actually viewed the posts. This was due to followers' account activity/inactivity, and because Instagram does not display posts in chronological order of posting. Instead, the order of posts displayed in the Instagram feed is based on algorithms unique to each user, resulting from the types of posts they have previously engaged with and posts that users they follow have engaged with.

The account followers were built up before the experiment began by following accounts that were related to child abuse, mental health, and resilience. The @resilienceinyouth account started the study period with 105 followers. Once the baseline week began, the @resilienceinyouth account only followed accounts that had already followed the @resilienceinyouth account first (i.e., a "follow-back") to avoid any interference in the number of new followers since number of followers was a study outcome variable.

\section{Ethics approvals}

Aggregated data derived from Instagram was analyzed. Individual user data or comments were not analyzed, thus minimizing the identification of individual users. Information was obtained from Instagram through the public portal (publicly available). The primary study site was McMaster University, with health research governed by the Hamilton Integrated Research Ethics Board, who waived formal ethics review for this study.

\section{Data analysis}

In order to conduct the manipulation checks, we examined three Instagram variables: followers, impressions, and clicks. We had two observations for each of three timepoints: baseline, Instagram On, and Instagram Off as described in the method. These data were each submitted to a repeated measures Analysis of Variance (ANOVA) with timepoint (baseline, Instagram On, Instagram Off) as the repeated measures variable. Significant effects of timepoint in the ANOVA were followed up by two sequential paired-sample t-tests comparing baseline to Instagram On, and then Instagram On to Instagram Off, respectively. One-tailed tests were used for these follow-up t-tests given that directional effects had been predicted a priori.

The hypothesis testing involved ResearchGate weekly reads (i.e., number of reads of the article referred to in the Instagram post). We had nine observations (i.e., nine research articles that were referred to in the Instagram posts; see Table 1 for the articles) for each of the three timepoints: baseline, Instagram On, and Instagram Off. In order to report weekly reads on ResearchGate, the reads across the two weeks for each timepoint were averaged prior to analysis. Then difference scores were calculated between Instagram On and baseline, and between Instagram On and Instagram Off for each participant. Because ResearchGate weekly reads is a cumulative variable, our main interest was whether the increase in reads was greater for the time when we were active on Instagram (i.e., the difference between Instagram On and baseline) as compared to the time when we were not active on Instagram (i.e., the difference between Instagram Off and Instagram On). We compared these two difference scores using a paired sample t-test. A one-tailed test was used given that directional effects had been predicted a priori. 
Alpha was set at 0.05 for all ANOVAs and paired sample t-tests. Marginal effects ( $p=.06)$ are mentioned. Effect sizes are reported for all analyses using partial eta squared $\left(\eta_{p}{ }^{2}\right)$ and are interpreted using the following guidelines: $\eta_{p}^{2}=.01$ is a small effect; $\eta_{p}^{2}=.06$ is a moderate effect; and $\eta_{p}^{2}=.14$ is a large effect (Cohen, 1988).

\section{Results}

\section{Characteristics of followers}

The majority of the account followers were females (71\%). With respect to age, the largest category of followers was those in the 18-24 years age range (34\%) capturing late adolescence and emerging adulthood; $7 \%$ of followers were in the 13-17 years age range of adolescence. The number of Instagram followers was a cumulative variable (i.e., followers tend to accumulate over time).

\section{Manipulation check}

Instagram Weekly Followers. Figure 1 shows the mean number of weekly followers at each timepoint (i.e., baseline, Instagram On, and Instagram Off). As can be seen, the data conformed to the expected ABA pattern given that this is a cumulative variable. Specifically, the mean number of weekly followers increased during the "Instagram On" timepoints ( $M=148.0$ followers) relative to baseline ( $M=110.5$ followers), and did not increase during the "Instagram Off" timepoints ( $M=148.0$ followers) relative to "Instagram On", respectively. The repeated measures ANOVA revealed a statistically significant within-subjects effect of timepoint: $f(2,2)=43.605, p=.022, \eta_{p}{ }^{2}=.978$. Paired sample t-tests revealed that there were significant increases of large magnitude in weekly followers for the "Instagram On" timepoints relative to the baseline timepoints $\left(t(1)=15.00, p=.021, \eta_{p}{ }^{2}=.996\right.$; see Figure 1$)$. In addition, there were no further changes (effects of inconsequential magnitude) in weekly followers for the "Instagram Off" timepoints relative to the "Instagram On" timepoints (the number of followers remained constant, see Figure 1).

Figure 1. Instagram Weekly Followers

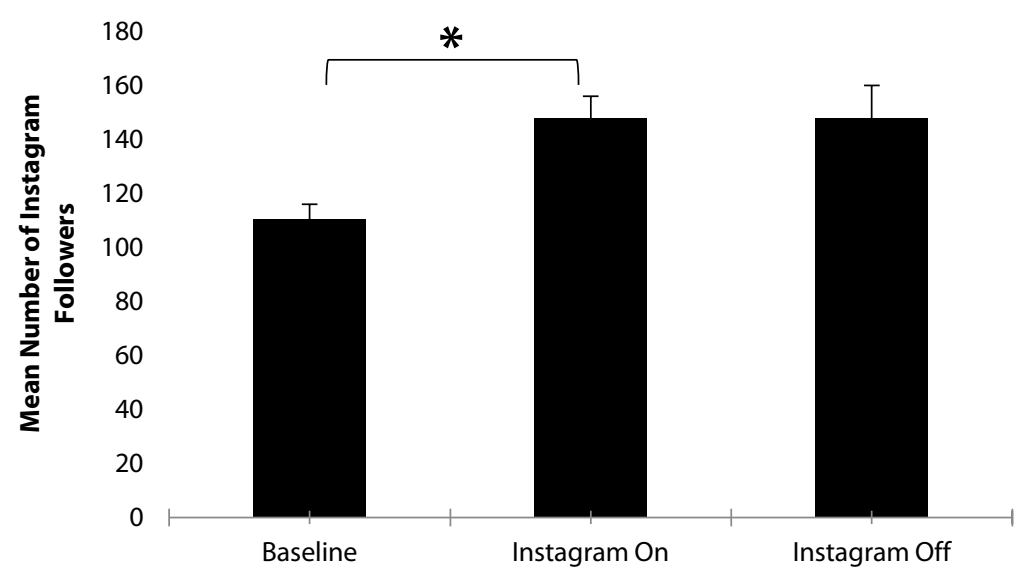

Note. Effects of Phase (Baseline vs. Instagram On vs. Instagram Off) on Instagram Engagement Variable: Mean Number of Weekly Instagram Followers. Error bars represent standard error. Significance of the difference in successive means is indicated via asterisks: ${ }^{*} p<0.05$ (onetailed).

Instagram Weekly Impressions. Figure 1.1 shows the mean number of weekly impressions at each timepoint (i.e., baseline, Instagram On, and Instagram Off). As can be seen, the data conformed to the expected ABA pattern with the mean number of weekly impressions increasing during the "Instagram On" timepoints $(M=2282.0)$ relative to baseline ( $M=448.5)$ and decreasing again during the "Instagram Off" timepoints ( $M=399.5)$ relative to "Instagram On", respectively. The repeated measures ANOVA revealed a statistically significant within-subjects effect of timepoint $\left(f(2,2)=223.467, p=.004, \eta_{p}{ }^{2}=.996\right)$. Paired sample t-tests revealed that there were significant increases of large magnitude in weekly impressions for the "Instagram On" timepoints relative to the baseline timepoints $(t(1)=18.81$, $p=.017, \eta_{p}^{2}=.997$; see Figure 1.1). In addition, there were significant decreases of large magnitude in weekly impressions for the "Instagram Off" timepoints relative to the "Instagram On" timepoints $(t(1)=-44.29, p=.007$, 
$\eta_{p}{ }^{2}=.999 ;$ see Figure 1.1). This pattern of findings supports an effective manipulation in the experimental variable of being active/non-active on Instagram in terms of Instagram impressions.

Figure 1.1. Instagram Weekly Impressions.

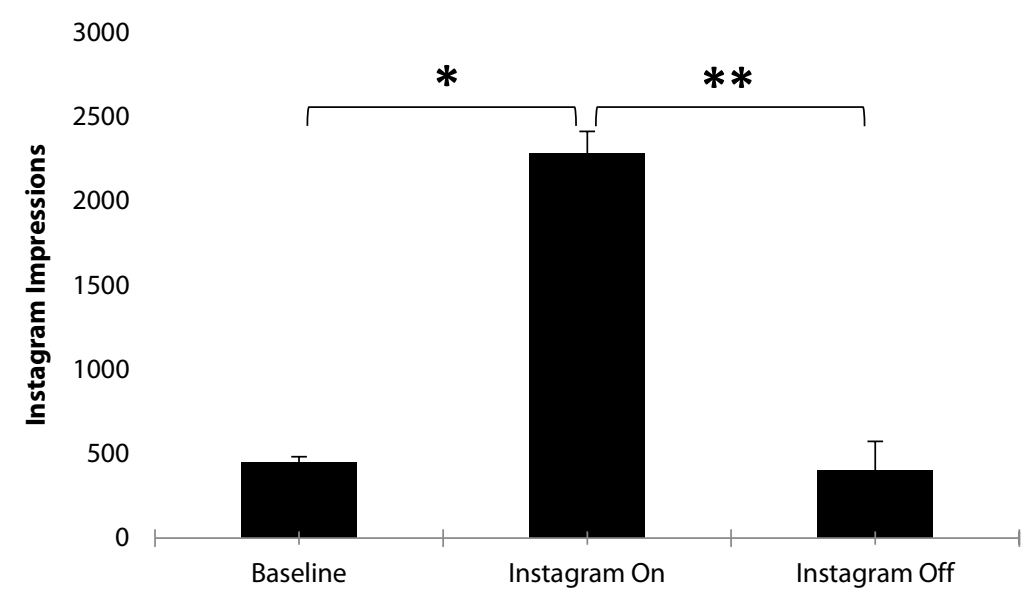

Note. Effects of Phase (Baseline vs. Instagram On vs. Instagram Off) on Instagram Engagement Variable: Mean Weekly Instagram Impressions. Error bars represent standard error. Significance of the difference in successive means is indicated via asterisks: ${ }^{* *} p<0.01 ;{ }^{*} p<0.05$ (one-tailed).

Instagram Weekly Website Clicks. Figure 1.2 shows the mean number of weekly website clicks at each timepoint (i.e., baseline, "Instagram On", and "Instagram Off" periods). As can be seen, the data conformed to the expected ABA pattern with the mean number of weekly website clicks increasing during the "Instagram On" timepoints $(M=7.5)$ relative to baseline $(M=2.5)$, and decreasing again during the "Instagram Off" timepoints $(M=0.0)$ relative to "Instagram On", respectively. The repeated measures ANOVA revealed a statistically significant within-subjects effect of timepoint $\left(F(2,2)=25.00, p=.038, \eta_{p}^{2}=.962\right)$. Paired sample t-tests revealed that there were marginally significant increases of large magnitude in weekly website clicks for the "Instagram On" timepoints, relative to the baseline timepoints $\left(t(1)=5.00, p=.063, \eta_{p}{ }^{2}=.962\right.$; see Figure 1.2) and marginally significant decreases of large magnitude in weekly website clicks for the "Instagram Off" timepoints relative to the "Instagram On" timepoints $(t(1)=-5.00, p=.063$, $\eta_{p}{ }^{2}=.962 ;$ see Figure 1.2).

Figure 1.2. Instagram Weekly Website Clicks.

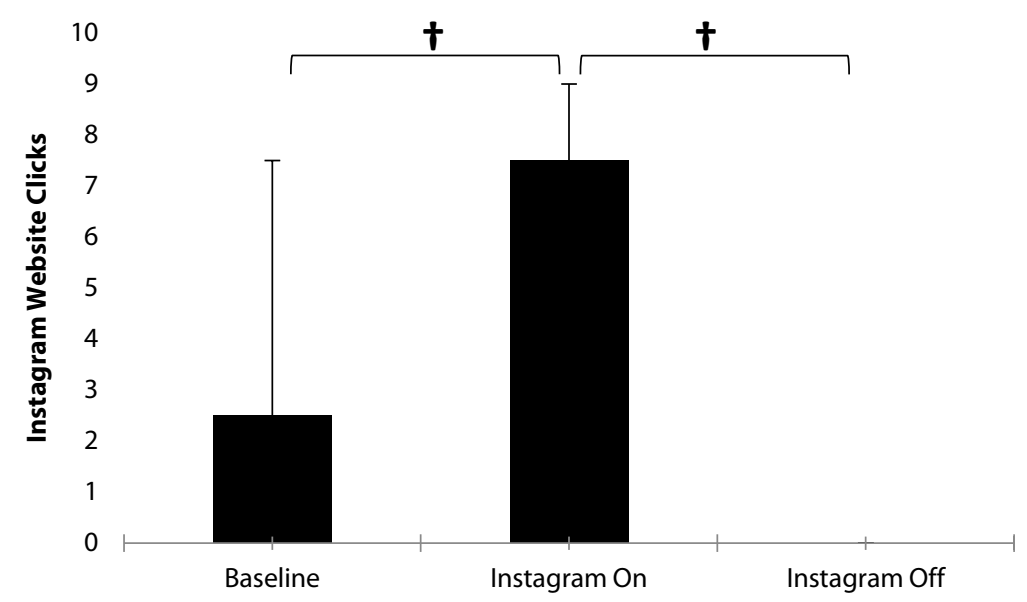

Note. Effects of Phase (Baseline vs. Instagram On vs. Instagram Off) on Instagram Engagement Variable: Mean Weekly Website Clicks. Error bars represent standard error. Significance of the difference in successive means is indicated via symbols: $\uparrow p=0.06$ (one-tailed). 


\section{Hypothesis test: Effects of Instagram postings on ResearchGate reads}

ResearchGate Weekly Reads. The mean number of ResearchGate reads at each timepoint was as follows: 184.6 $(S E=27.73)$ reads at baseline, $218.8(S E=29.19)$ reads for "Instagram On", and $225.4(S E=29.91)$ reads for "Instagram Off" periods, respectively. Note that the ResearchGate reads values are cumulative values. Thus, the mean number of weekly reads increased during the "Instagram On" timepoints relative to baseline, as expected, but further increased during the "Instagram Off" timepoints relative to "Instagram On", as well. To determine if there were greater increases from baseline to "Instagram On" relative to the time frame of "Instagram On" to "Instagram Off", we calculated difference scores between each of these timepoints. These difference scores were then subject to a paired samples t-test (see Figure 2) which showed that the degree of increase in ResearchGate reads was significantly greater when Instagram was turned on (relative to baseline), than when Instagram was turned off (relative to Instagram On), and that this difference was large in magnitude $\left(t(8)=6.92, p<.001, \eta_{p}{ }^{2}=.854\right.$; see Figure 2.0). Thus, the increase in ResearchGate reads of the papers that were posted on Instagram was almost five times greater when we were active on Instagram compared to when we were not.

Figure 2. ResearchGate Weekly Reads.

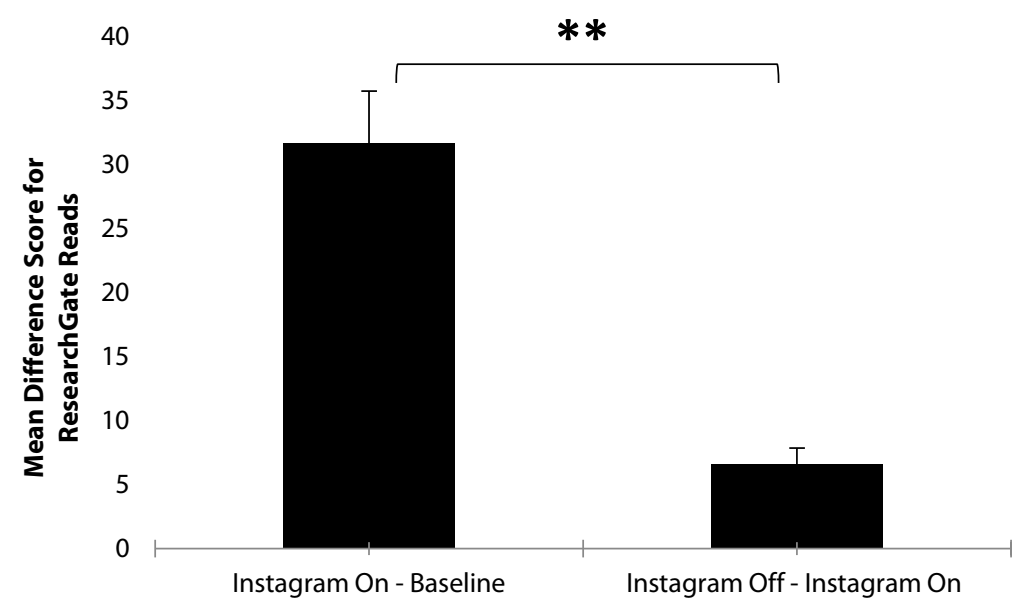

Note. Mean Difference Score for Weekly ResearchGate Reads. Difference scores were calculated as change from the previous condition (i.e., Instagram On - Baseline; Instagram Off - Instagram On). Error bars represent standard error. Significance indicated with asterisk: ${ }^{* *} p<0.01$ (onetailed).

\section{Discussion}

This experiment demonstrated that regular posting on Instagram was a useful tool for reaching the public, including youth, with research information on risk and resilience. Instagram posting led to large increases in followers, impressions, and website clicks within Instagram, and to large increases in the number of reads of the corresponding research articles on ResearchGate. Thus, it demonstrated preliminary evidence of Instagram as an effective knowledge mobilization platform for sharing research about sensitive health-related topics with the public.

Regular Instagram posting of research related to risk and resilience led to increases in the number of individuals following the experiment's Instagram account - one indicator of reach of the information. During weeks of daily posting, relative to the baseline, more new Instagram followers were engaged. This effect was large in magnitude, attesting to its practical importance. Although this was a cumulative variable, no further significant increase in the number of Instagram followers were observed during subsequent weeks of no daily Instagram posting. This attests to the importance of being very active in Instagram posting in order to accumulate followers with whom to share health information.

Regular posting on the Instagram account also led to an increase in the number of Instagram impressions the number of times the posts were viewed. Active posting led to a substantial increase in the number of Instagram impressions (relative to baseline); no posting led to a substantial decrease in the number of Instagram impressions 
Instagram as a knowledge mobilization platform for youth resilience research: An exploratory study

(relative to periods of active Instagram posting). This finding confirms that active posting results in greater viewing of a research-based message (i.e., greater engagement) by an account's followers.

In addition, posting regularly on Instagram resulted in an increase in the number of Instagram website clicks. This means that active Instagram posting led to increases in the account followers actively clicking on the associated link to take them to the research article page on ResearchGate, where they could see the article's title, authors, and abstract. The increases in website clicks with active Instagram posting (relative to baseline) and decreases in website clicks with no Instagram posting (relative to Instagram On periods) were both large in magnitude. This suggests that these were likely meaningful differences despite being trends in terms of statistical significance ( $p=.06$ in each case). With greater engagement and higher numbers of followers, the research evidence being shared is more likely to be actively mobilized to more people.

The most important outcome of this experiment was showing that active posting on Instagram leads to an increase in reads of the associated article on ResearchGate. This means that not only did followers click more often on the embedded link to take them to the article's title, authors and abstract on ResearchGate, but also, they more often actively opened the article to engage further with the material (i.e., increased ResearchGate 'reads' of our shared articles). The general upward trend of reads of our shared articles on ResearchGate is to be expected as this is a cumulative variable. However, the use of an ABA design, and our employment of $d$-scores, allowed us to show that there was a significantly greater increase in ResearchGate reads of the shared articles when the account was actively posting about the articles' results, than when it was not. This large magnitude result is supportive of Instagram's usefulness in mobilizing research articles on adolescent mental health and resilience to the public. The results of this experiment, including the increases in Instagram followers, impressions, and website clicks and ResearchGate reads during periods of Instagram posting activity, indicate that the public, as social media users on a network such as Instagram, will engage with messages related to sensitive topics. This suggests that Instagram can be a useful tool for mobilizing research-based information about such sensitive topics to users who would benefit from the knowledge (e.g., young people themselves). This suggests that it is a feasible strategy for a research team to utilize in their knowledge dissemination and impact planning, as the extent of the cross-reach from scholarship repositories to a range of social media message formats can be directly tested. For example, using a ResearchGate project account that houses team member's articles in one locale, could be used to gage the number of project followers from the academic community, and the number of new reads and citations over the longer-term investigation.

It is important to note the characteristics of the followers we reached with this Instagram intervention. First, most followers engaged by the end of the experiment were women (71\%), and the largest age group comprised those in the late adolescent/emerging adulthood developmental stage (i.e., 18-24 years; $34 \%$ ). The finding that most followers were women is unsurprising, given that prior work has shown gender differences in the purposes of internet usage, with women being more likely to use for educational purposes than men (Weiser, 2000). Given that most of the account followers were women, findings cannot necessarily be generalized to all Instagram users. Research has found that males may be more difficult to engage in mental health-related communications (Ogrodnikzuk et al., 2016; Johnson et al., 2012). Future studies should review guidelines and strategies for engaging male youth in health-related topics online. With regards to the age effect, while we were effective in recruiting many followers in the age range to whom the results are most relevant (i.e., adolescents and emerging adults), it is important to note that many of the followers were outside this age range. It is possible that parents, for example, engaged with the Instagram account to gain information relevant to their adolescent offspring. A relatively small percent (7\%) were younger teens; thus, future research is needed on how to more effectively reach these distinct stakeholder groups for such adolescent mental health and resilience content.

By increasing knowledge of research-based findings in youth health risk and resilience, it is hoped that this might lead to improved resilience behaviour, although this was not tested in the current study. Further, in targeting youth, it is important to consider the impact SoMe usage itself may have on young people's mental health. It has been suggested that increased use of SoMe may negatively impact an individual's wellbeing, leading to symptoms of depression or anxiety, for example, perhaps as a result of social comparison of oneself to the positive images generally projected by others over SoMe (Hardy \& Castonguay, 2018). This suggests that the usage of SoMe sites may have the potential to be more detrimental to one's mental health than helpful. However, research does not appear to support this theory in younger people. For example, a study by Jelenchick and colleagues (2013) demonstrated no significant association between the use of SoMe sites and depression levels in older adolescent university students and, instead, supported the idea of using such sites for the purpose of combating mental health stigma and promoting wellbeing. 
Instagram as a knowledge mobilization platform for youth resilience research: An exploratory study

In addition, though using multiple SoMe platforms has been linked to increased anxiety in adults aged 30 years and above, the opposite relationship was observed in emerging adults, who experienced better mental wellbeing alongside use of more SoMe platforms (Hardy \& Castonguay, 2018). Based on such evidence, harms associated with SoMe use appear less relevant to the younger population; although this certainly merits continued study.

\section{Limitations and implications for future research}

This study does possess several noteworthy limitations and therefore, the results should be interpreted with caution. This is the first Instagram knowledge mobilization experiment to our knowledge and therefore, the methodological design was not grounded in any other theoretical designs. Thus, this study is exploratory in nature. Due to Instagram's design, our account's posts were not displayed chronologically to followers (i.e., they would not appear in the order in which they were posted). Instead, posts were displayed to users in an order determined by an Instagram algorithm. This algorithm attempts to predict posts that the particular user would like most (based on their smartphone history, previous Instagram engagement, internet usage, phone GPS), and presents those posts first. As a result, our collected data may not be completely accurate in its demonstration of engagement, as our posts would not be displayed to all users in the same order or at the same time. Those who were following more Instagram accounts (i.e., more active SoMe users) or had previously engaged more with unrelated topics would have a lower chance of seeing the account posts in their newsfeed. In addition, if a post made by the @resilienceinyouth account was reposted by a user (i.e. shared by another user from their own account), there is no accurate way of knowing that this further dissemination of research was occurring. All of the Instagram statistics used are based on the activity of our Instagram followers and we are not able to report on, or statistically analyze, the engagement of non-follower users. Another limitation is the small "sample size" (i.e., only nine research-based articles; only two weeks of data per phase) which resulted in low power for detecting some of our expected effects. For example, the changes in website clicks observed with our ABA design were only marginally significant $(p=.06)$, and this was likely secondary to low power, particularly since the expected effects were large in magnitude. Future such studies should post a larger number of articles across a longer period of time. A further limitation pertains to the short duration of the study (i.e., six weeks) which prevented us from examining longer term outcomes of our Instagram posting intervention such as impact on citations of the articles posted in ResearchGate. In fact, another similarly designed study by our team that was longer in duration (i.e., seven months) showed that posting research-based information on Twitter led to significant increases in citations of the ResearchGate articles to which the tweets pertained (Wekerle et al., 2018).

Another potential limitation of the study was the fact that general interest, non-research based posts about resilience, in addition to the research-based posts, were also posted during each "Instagram On" phase during the experiment, albeit less frequently (i.e., ratio of two research study specific posts to every one general interest, nonresearch study specific post). As the latter were not linked to a specific research article, we could not examine their impacts on Instagram website clicks or ResearchGate article reads. Moreover, although their impact is included within the presented statistics on Instagram impressions, there is no way to separate the number of impressions for these two types of posts because Instagram only provides one single figure for impressions per Instagram account. Future research is thus needed to determine whether our observed effects of the research study specific Instagram posts require the additional presence of such non-research study specific posts to generate general interest in the Instagram account.

Although this study explored users' engagement with youth risk and resilience research- and evidence- based posts within Instagram, as well as the translation of Instagram engagement to interaction with the research content on ResearchGate, data collection was limited in terms of how the information was mobilized. For example, there is no way to identify how this information was used specifically by those who interacted with it. Future research focused on Instagram users may opt for a different design whereby participants sign on to participate in the study to allow for a follow-up data collection phase that queries actions taken based on information (e.g., influenced personal health decision-making, shared with youth advocates, used in agency reports, etc.)

Utilizing SoMe and smartphone technology, as widely used as it is by youth, may be a beneficial tool for risk and resilience knowledge mobilization, especially among the adolescent and emerging adult population. While our Instagram findings are promising, further research is required on Instagram as a knowledge mobilization tool, as its utility in this regard is not as well-documented in the research literature, as compared to other SoMe sites (e.g., Twitter, Facebook). Based on the observations from this study, however, Instagram appears to be a potentially effective and viable platform that merits further research. 


\section{Funding}

This work was supported by the Canadian Institute for Health Research (CIHR; TE3-138302, 2014).

\section{Conflict of interest}

The authors have no conflict of interest to disclose.

\section{References}

Ahn, J. (2014) It's complicated: The social lives of networked teens; The app generation: How today's youth navigate identity, intimacy, and imagination in a digital world. Journal of Children and Media, 8(3), 313-316. https://doi.org/10.1080/17482798.2014.923607

Arnett, J. J. (2000). Emerging adulthood: A theory of development from the late teens through the twenties. American Psychologist, 55(5), 469-480. https://doi.org/10.1037//0003-066X.55.5.469

Best, P., Manktelow, R., \& Taylor, B. (2016). Social work and social media: Online help-seeking and the mental well-being of adolescent males. British Journal of Social Work, 46(1), 257-276. https://doi.org/10.1093/bjsw/bcu130

Boak, A., Hamilton, H. A., Adlaf, E. M., \& Mann, R. E. (2017). Drug use among Ontario students, 1977-2017: Detailed findings from the Ontario Student Drug Use and Health Survey. Centre for Addiction and Mental Health. https://www.camh.ca/en/science-andresearch/institutes-and-centres/institute-for-mental-health-policy-research/ontario-student-drug-use-and-health-survey--osduhs

Bronfenbrenner, U. (1979). The ecology of human development: Experiments by nature and design. Harvard University Press.

Bronfenbrenner, U. (2005). Making human beings human: Bioecological perspectives on human development. Sage.

Bull, S. S., Levine, D. K., Black, S. R., Schmiege, S. J., \& Santelli, J. (2012). Social media-delivered sexual health intervention: A cluster randomized controlled trial. American Journal of Preventive Medicine, 43(5), $467-474$. https://doi.org/10.1016/j.amepre.2012.07.022

Bundy, D. A., de Silva, N., Horton, S., Patton, G. C., Shultz, L., \& Jamison, D. T. (2017). Investment in child and adolescent health and development: Key messages from Disease Control Priorities, 3 $3^{\text {rd }}$ Edition. The Lancet Review, 391(10121), $687-699$. https://doi.org/10.1016/S0140-6736(17)32417-0

Child Helpline International (2014). The voices of children and young people. http://www.childhelplineinternational.org/media/122286/14746_chi_voc_report_web_singlepages25.11.14.pdf

Cohen, J. (1988) Statistical power analysis for the behavioral sciences (2nd ed.). Erlbaum.

Craig, S. L., McInroy, L., McCready, L. T., \& Alaggia, R. (2015). Media: A catalyst for resilience in lesbian, gay, bisexual, transgender, and queer youth. Journal of LGBT Youth, 12(3), 254-275. https://doi.org/10.1080/19361653.2015.1040193

D’Avanzo, B., Barbato, A., Erzegovesi, S., Lampertico, L., Rapisarda, F., \& Valsecchi, L. (2012). Formal and informal help-seeking for mental health problems. A survey of preferences of Italian students. Clinical Practice and Epidemiology in Mental Health, 8, 4751. https://doi.org/10.2174/1745017901208010047

Dowshen, N., Lee, S., Lehman, B. M., Castillo, M., \& Mollen, C. (2015). IknowUshould2: feasibility of a youth-driven social media campaign to promote STI and HIV testing among adolescents in Philadelphia. AIDS \& Behavior, 19(2), 106-111. https://doi.org/10.1007/s10461-014-0991-9

Dufty, N. (2012). Using social media to build community disaster resilience. The Australian Journal of Emergency Management, 271), 40-45. https://search.informit.com.au/documentSummary; $d n=046981962746932$;res=IELAPA

Eaton, P. W. (2014). Viewing digital space(s) through Bronfenbrenner's Ecological Model. https://profpeaton.com/2014/05/11/viewing-digital-spaces-through-bronfenbrenners-ecological-model/

Edison Research \& Triton Digital. (2017). The infinite dial 2017. https://www.edisonresearch.com/infinite-dial-2017/

Frith, E. (2017). Social media and children's mental health: A review of the evidence. Education Policy Institute. https://epi.org.uk/wp-content/uploads/2018/01/Social-Media_Mental-Health_EPI-Report.pdf

Giannoulakis, S., \& Tsapatsoulis, N. (2016). Evaluating the descriptive power of Instagram hashtags. Journal of Innovation in Digital Ecosystems, 3(2), 114-129. https://doi.org/10.1016/j.jides.2016.10.001

Hardy, B. W., \& Castonguay, J. (2018). The moderating role of age in the relationship between social media use and mental wellbeing: An analysis of the 2016 General Social Survey. Computers in Human Behavior, 85, $282-290$. https://doi.org/10.1016/j.chb.2018.04.005 
Instagram as a knowledge mobilization platform for youth resilience research: An exploratory study

Hu, Y., Manikonda, L., \& Kambhampati, S. (2014). What we instagram: A first analysis of instagram photo content and user types. In Proceedings of the 8th International Conference on Weblogs and Social Media, ICWSM 2014 (pp. 595-598). The AAAI Press.

Jelenchick, L. A., Eickhoff, J. C., \& Moreno, M. A. (2013). "Facebook depression?" Social networking site use and depression in older adolescents. Journal of Adolescent Health, 52(1), 128-130. https://doi.org/10.1016/j.jadohealth.2012.05.008

Johnson, J. L., Oliffe, J. L., Kelly, M. T., Galdas, P., \& Ogrodniczuk, J. S. (2012). Men's discourses of help-seeking in the context of depression. Sociology of Health \& IIIness, 34(3), 345-361. https://doi.org/10.1111/j.1467-9566.2011.01372.x

Jurgens, M., \& Helsloot, I. (2018). The effect of social media on the dynamics of (self) resilience during disasters: A literature review. Journal of Contingencies and Crisis Management, 26(1), 79-88. https://doi.org/10.1111/1468-5973.12212

Kann, L., McManus, T., Harris, W. A., Shanklin, S. L., Flint, K. H., Queen, B., Lowry, R., Chyen, D., Whittle, L., Thornton, J., Lim, C., Bradford, D., Yamakawa, Y., Leon, M., Brener, N, \& Ethier, K. A. (2018). Youth risk behavior surveillance-United States, 2017. MMWR Surveillance Summaries, 678), 1-114. https://www.cdc.gov/mmwr/volumes/67/ss/ss6708a1.htm

Kaufmann, M. (2015). Resilience 2.0: Social media use and (self-)care during 2011 Norway attacks. Journal of Media, Culture \& Society, 3777) 972-987. https://doi.org/10.1177/0163443715584101

Kazdin, A. E. (2011) Single-case research designs: Methods for clinical and applied settings (2nd Ed.). Oxford University Press.

Lambert, D. N., Bishop, L. E., Guetig, S., \& Frew, P. M. (2014). A formative evaluation of a social media campaign to reduce adolescent dating violence. JMIR Research Protocols, 3(4), Article e64. https://doi.org/10.2196/resprot.3546

Lamblin, M., Murawski, C., Whittle, S., \& Fornito, A. (2017). Social connectedness, mental health and the adolescent brain. Neuroscience \& Biobehavioral Reviews, 80, 57-68. https://doi.org/10.1016/j.neubiorev.2017.05.010

Lenhart, A. (2015). Teens, social media \& technology overview 2015. Pew Research Center's Internet \& American Life Project. https://www.pewresearch.org/internet/2015/04/09/teens-social-media-technology-2015/

Lenhart, A., Duggan, M., Perrin, A., Stelper, R., Rainie, L., \& Parker, K. (2015). Teens, social media \& technology overview 2015. Smartphones facilitate shift in communication landscape for teens. Pew Research Center's Internet \& American Life Project.

Lenhart, A., Purcell, K., Smith, A., \& Zickuhr, K. (2010). Social media \& mobile internet use among teens and young adults. PEW Research Center's Internet \& American Life Project.

Mustanski, B. S., Newcomb, M. E., Du Bois, S. N., Garcia, S. C., \& Grov, C. (2011). HIV in young men who have sex with men: A review of epidemiology, risk and protective factors, and interventions. Journal of Sex Research, 48(2-3), 218-253. https://doi.org/10.1080/00224499.2011.558645

O'Connell, M. E., Boat, T., \& Warner, K. E. (2009). Preventing mental, emotional, and behavioral disorders among young people: Progress and possibilities (Vol. 7). National Academies Press. https://doi.org/10.17226/12480

O'Donnell, N. H., \& Willoughby, J. F. (2017). Photo-sharing social media for eHealth: Analysing perceived message effectiveness of sexual health information on Instagram. Journal of Visual Communication in Medicine, 40(4), $149-159$. https://doi.org/10.1080/17453054.2017.1384995

Ogrodnikzuk, J., Oliffe, J., Kuhl, D., \& Gross, P. A. (2016). Men's mental health: Spaces and places that work for men. Canadian Family Physician, 62(6), 463-464. https://www.cfp.ca/content/cfp/62/6/463.full.pdf

O'Keeffe, G. S., \& Clarke-Pearson, K. (2011). The impact of social media on children, adolescents, and families. Pediatrics, 127(4), 800804. https://doi.org/10.1542/peds.2011-0054

Ortiz, R. R., Shafer, A., Cates, J., \& Coyne-Beasley, T. (2018). Development and evaluation of a social media health intervention to improve adolescents' knowledge about vaccination against the Human Papillomavirus. Global Pediatric Health, 5, 1-10. https://doi.org/10.1177/2333794X18777918

Pew Research Center. (2018a). How teens and parents navigate screen time and device distractions. PEW Research Center. http://www.pewinternet.org/2018/08/22/how-teens-and-parents-navigate-screen-time-and-device-distractions/

Pew Research Center. (2018b). Teens, social media \& technology 2018. PEW Research Center. http://www.pewinternet.org/2018/05/31/teens-social-media-technology-2018/

Pretorius, C., Chambers, D., \& Coyle, D. (2019). Young People's Online Help-Seeking and Mental Health Difficulties: Systematic Narrative Review. Journal of Medical Internet Research, 21(11), Article e13873. https://doi.org/10.2196/13873

Rice, S. M., Goodall, J., Hetrick, S. E., Parker, A. G., Gilbertson, T., Amminger, G. P., Davey, C. G., McGorry, P. D., Gleeson, J., \& AlvarezJimenez, M. (2014). Online and social networking interventions for the treatment of depression in young people: A systematic review. Journal of Medical Internet Research, 16(9), Article e206. https://doi.org/10.2196/jmir.3304

Rideout, V., Fox, S., \& Well Being Trust. (2018). Digital health practices, social media use, and mental well-being among teens and young adults in the U.S. Articles, Abstracts, and Reports, 1093. https://digitalcommons.psjhealth.org/publications/1093 
Rushing, S. C., \& Stephens, D. (2011). Use of media technologies by Native American teens and young adults in the Pacific Northwest: Exploring their utility for designing culturally appropriate technology-based health interventions. The Journal of Primary Prevention, 32(3-4), 135-145. https://doi.org/10.1542/peds.2011-0054

Sheldon, P., \& Bryant, K. (2016). Instagram: Motives for its use and relationship to narcissism and contextual age. Computers in Human Behavior, 58, 89-97. https://doi.org/10.1016/j.chb.2015.12.059

Sigalit, W., Sivia, B., \& Michal, I. (2017). Factors Associated with nursing students' resilience: Communication skills course, use of social media and satisfaction with clinical placement. Journal of Professional Nursing, 33(2), 153-161. https://doi.org/10.1016/j.profnurs.2016.08.006

Szlyk, H., Deng, J., Xu, C., Krauss, M. J., \& Cavazos-Rehg, P. A. (2020). Leveraging social media to explore the barriers to treatment among individuals with depressive symptoms. Depression and Anxiety. 375), 458-465. https://doi.org/10.1002/da.22990

Taylor, M., Wells, G., Howell, G., \& Raphael, B. (2012). The role of social media as psychological first air as a support to community resilience building. Australian Journal of Emergency Management, 271), 20-26. https://knowledge.aidr.org.au/resources/ajem-jan-2012-the-role-of-social-media-as-psychological-first-aid-as-a-support-tocommunity-resilience-building-a-facebook-study-from-cyclone-yasi-update/

Ungar, M. (2008). Resilience across cultures. The British Journal of Social Work, 38, 218-235. https://doi.org/10.1093/bjsw/bcl343

Ungar, M., \& Theron, L. (2020). Resilience and mental health: How multisystemic processes contribute to positive outcomes. The Lancet Psychiatry, 75), 441-448. https://doi.org/10.1016/\$2215-0366(19)30434-1

Valkenburg, P. M., Peter, J., \& Schouten, A. P. (2006). Friend networking sites and their relationship to adolescents' well-being and social self-esteem. CyberPsychology and Behavior, 9(5), 584-590. https://doi.org/10.1089/cpb.2006.9.584

Wartella, E., Rideout, V., Montague, H., Beaudoin-Ryan, L., \& Lauricella, A. (2016). Teens, health and technology: A national survey. Media and communication, 4(3), 13-23. https://doi.org/10.17645/mac.v4i3.515

Weiser, E. B. (2000). Gender differences in internet use patterns and internet application preferences: A two-sample comparison. CyberPsychology \& Behavior, 3(2), 167-178. https://doi.org/10.1089/109493100316012

Wekerle, C., Vakili, N., Stewart, S., \& Black., T. (2018). The utility of Twitter as a tool for increasing reach of research on sexual violence. Child Abuse \& Neglect, 85, 220-228. https://doi.org/10.1016/j.chiabu.2018.04.019

Wekerle, C., Waechter, R., \& Chung, R. (2011). Contexts of vulnerability and resilience: Childhood maltreatment, adolescent cognitive functioning and close relationships. In M. Ungar (Ed.), The Social Ecology of Resilience (pp. 187-198). Springer. https://doi.org/10.1007/978-1-4614-0586-3_16

Whiting, A., \& Williams, D. L. (2013). Why people use social media: A uses and gratifications approach. Qualitative Market Research: An International Journal, 16(4), 362-369. https://doi.org/10.1108/QMR-06-2013-0041

World Health Organization. (2018). Standards for improving the quality of care for children and young adolescents in health facilities. WHO Document Production Services. https://apps.who.int/iris/bitstream/handle/10665/272346/9789241565554eng.pdf?ua=1

Zardo, P., Barnett, A. G., Suzor, N., \& Cahill, T. (2018). Does engagement predict research use? An analysis of The Conversation Annual Survey 2016. PloS one, 13(2), Article e019229. https://doi.org/10.1371/journal.pone.0192290

Zemmels, D. R. (2012). Youth and new media: Studying identity and meaning in an evolving media environment. Communication Research Trends, 31(4), 4-22. http://cscc.scu.edu/trends/v31/CRT_v31_n4_December_2012.pdf

Zenone, M., Irving, P., Cianfrone, M., Lockhart, L., Costales, S., Cruz, K., \& Ignacio, J. (2020). Increasing awareness of a provincial mental health resource for boys and young men 12 to 17 years: Reflections from Foundry's Province-Wide Campaign. Health Promotion Practice, 21(5), 684-686. https://doi.org/10.1177/1524839920910695 